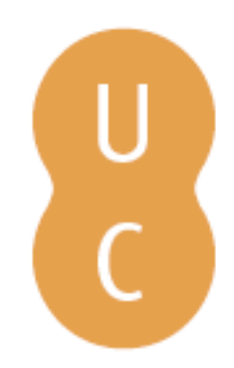

\title{
nombalina
}

\section{Espaço público}
Autor(es):
Amurane, António de; Pires, Fernando
Publicado por: Imprensa da Universidade de Coimbra
URL persistente:
URI:http://hdl.handle.net/10316.2/44312
DOI:
DOI:https://doi.org/10.14195/978-989-26-1556-1_7

Accessed : $\quad$ 26-Apr-2023 07:33:48

A navegação consulta e descarregamento dos títulos inseridos nas Bibliotecas Digitais UC Digitalis, UC Pombalina e UC Impactum, pressupõem a aceitação plena e sem reservas dos Termos e Condições de Uso destas Bibliotecas Digitais, disponíveis em https://digitalis.uc.pt/pt-pt/termos.

Conforme exposto nos referidos Termos e Condições de Uso, o descarregamento de títulos de acesso restrito requer uma licença válida de autorização devendo o utilizador aceder ao(s) documento(s) a partir de um endereço de IP da instituição detentora da supramencionada licença.

Ao utilizador é apenas permitido o descarregamento para uso pessoal, pelo que o emprego do(s) título(s) descarregado(s) para outro fim, designadamente comercial, carece de autorização do respetivo autor ou editor da obra.

Na medida em que todas as obras da UC Digitalis se encontram protegidas pelo Código do Direito de Autor e Direitos Conexos e demais legislação aplicável, toda a cópia, parcial ou total, deste documento, nos casos em que é legalmente admitida, deverá conter ou fazer-se acompanhar por este aviso.

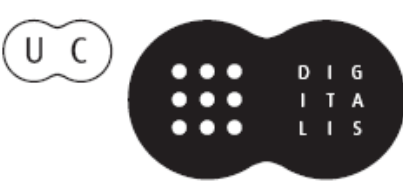




\section{OFICINAS DE \\ MUHIPITI \\ planeamento estratégico \\ património \\ desenvolvimento}

organização:

Walter Rossa

Nuno Lopes

Nuno Simão Gonçalves

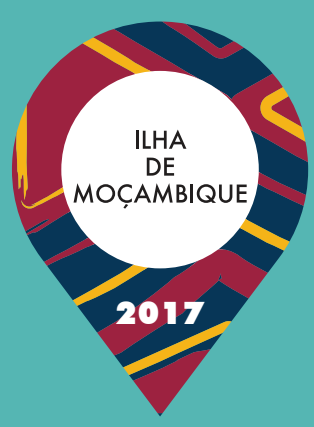




\section{ESPAÇO PÚBLICO}

\section{António de Amurane Fernando Pires}

\section{Missão-encomenda previamente formulada}

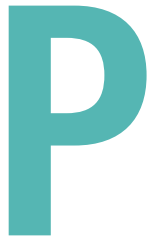

retende-se que, a partir de uma avaliação e tipificação de situações dos espaços públicos da Ilha, esta oficina produza um quadro de intervenção com exercícioscaso muito diversos que ilustrem o tipo e estratégia que se afiguram necessários empreender. É fundamental que, nessa avaliação prévia, sejam identificados os usos atuais e potenciais dos espaços existentes, no que não são de forma alguma descartáveis as questões de ordem simbólica e de representação. Chama-se a atenção para a necessidade de levar em linha de conta: custos das soluções, fácil acesso aos materiais e à mão de obra especializada necessária, durabilidade face aos requisitos locais, tipificação de soluções por forma a reduzir custos e dificuldades de gestão de estaleiro e armazém de reparações e reposições, impacto estético num bem com a distinção patrimonial detida pela Ilha, otimização e reutilização de materiais e/ ou soluções existentes. Em suma, um apelo ao bom senso em que a excelência do desenho deve resultar da aplicabilidade e não do efeito em projeto. Seria louvável que um dos resultados do trabalho desta oficina fosse um manual prático para a qualificação do espaço público da Ilha, à imagem de muitas que se conhecem, razão pelo qual a equipa se deverá ter previamente inteirado de alguns exemplos. 


\section{INTRODUÇÃO}

A partir de uma avaliação e tipificação de situações dos espaços públicos da Ilha, esta oficina teve como tarefa a produção de um quadro de intervenções, com dois exercícios-casos muito diversos, que ilustrem o tipo e estratégia que se afiguram necessários empreender. Nessa avaliação prévia seriam identificados os usos atuais e potenciais dos espaços existentes, incluindo as questões de ordem simbólica e de representação. Era, desde logo, importante levar em linha de conta os custos das soluções, a acessibilidade aos materiais e à mão de obra especializada necessária, a durabilidade face aos requisitos locais, a tipificação de soluções (reduzindo custos e dificuldades de gestão de estaleiro e armazém), o impacto estético num bem com a distinção patrimonial detida pela llha, a otimização e a reutilização de materiais e/ou soluções existentes.

Note-se que as características dos espaços públicos da llha abarcam, naturalmente, as várias dimensões temporais e espaciais que foram acompanhando a dinâmica de ocupação de diferentes povos que a cruzaram ou se foram estabelecendo nesta área, o que nos alerta para a existência de uma multiplicidade de culturas espaciais que é preciso ter em conta. Um segundo aspeto a não descurar é o facto de a llha ter um clima tropical húmido e um ecossistema próprio que, no seu conjunto, determinou características construtivas específicas do seu edificado, tanto ao nível de estruturas e materiais de construção, quanto à forma da distribuição dos espaços. Por isso, o desenho de uma estratégia de intervenção para os espaços públicos da Ilha passa, necessariamente, por ter em conta estes aspetos, constituindo uma ferramenta importante para a salvaguarda e desenvolvimento do seu património material e imaterial.

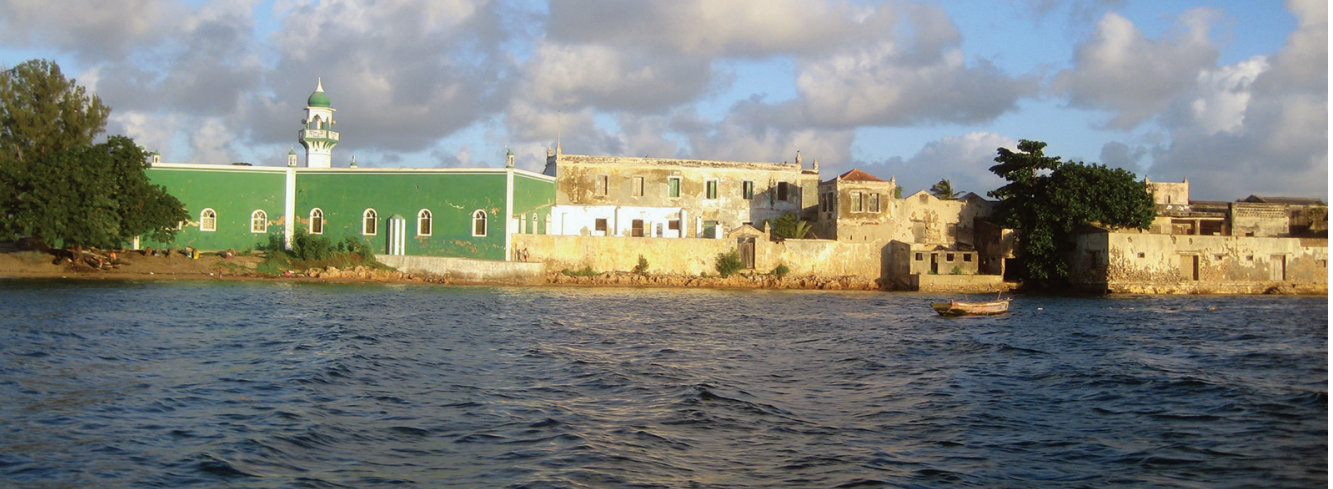


A estrutura urbanística da llha é composta por dois setores com características bem distintas: a cidade de pedra e cal e a cidade de macuti. A cidade de macuti ocupa a parte a sul do hospital, foi o espaço onde maioritariamente se instalou a população autóctone em casas de tipos tradicionais, cuja marca fundamental é, precisamente, as coberturas em macuti. A cidade de pedra e cal ocupa a área restante, a norte, onde não só se instalaram os colonizadores europeus e os seus equipamentos, mas também comerciantes das mais diversas origens. Por isso, ali se encontram os edifícios mais emblemáticos da cidade.

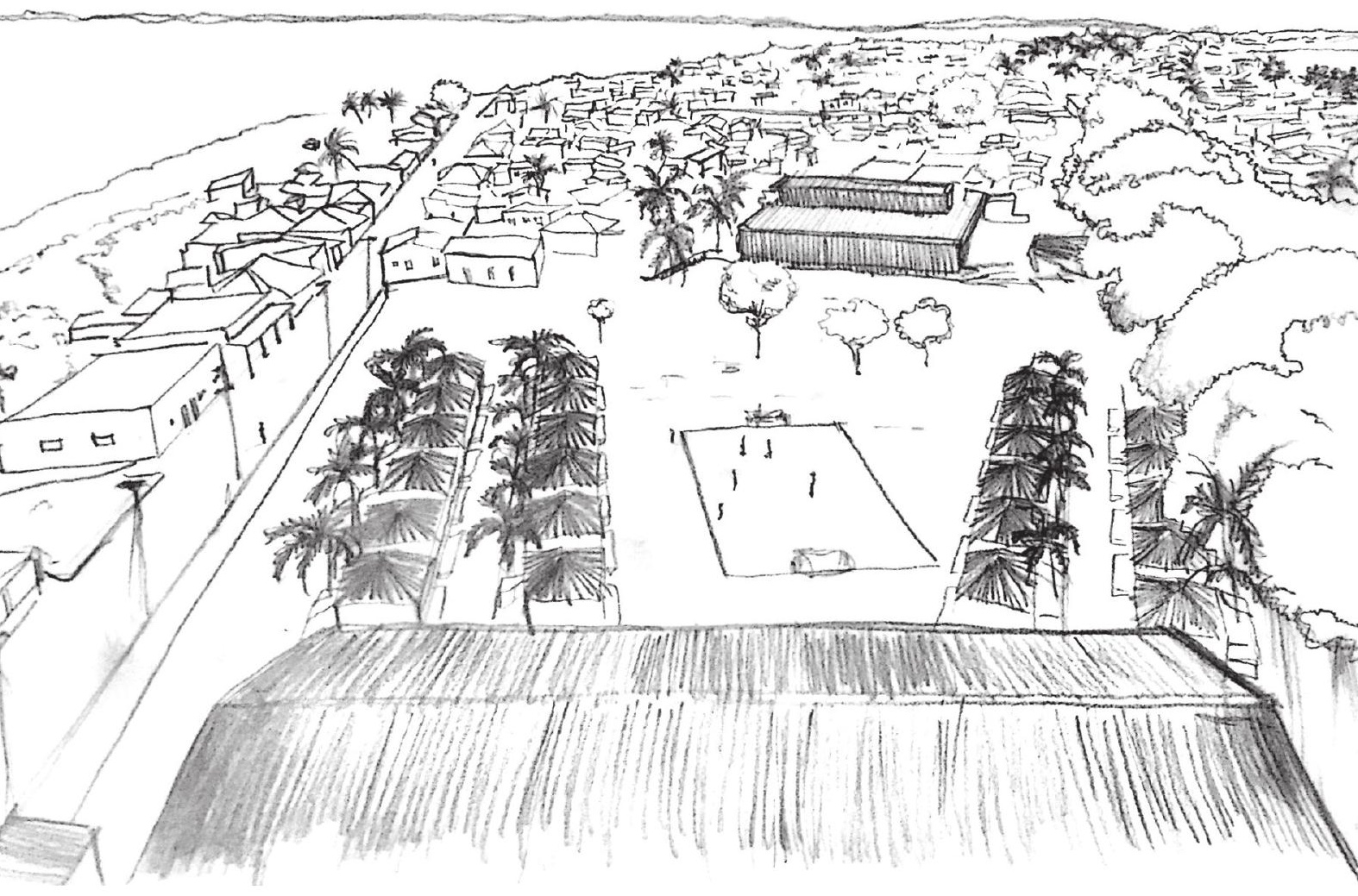


Perante esta realidade espacial, o desafio principal desta oficina foi encontrar respostas que levem em consideração essas diferenças, mas que também visem a integração da cidade, de forma a que a população usufrua dos espaços públicos como um todo. É ainda necessário potenciar e desenvolver a consolidação de diferentes tipos de espaços públicos servindo e estruturando toda a llha.

Da análise efetuada tornou-se claro que o elemento mais importante da rede dos espaços públicos da Ilha, até porque assegura a ligação entre as cidades, é o eixo formado pela avenida 25 de Junho. 0 troço que atravessa a cidade de macuti é, seguramente, um dos mais importantes lugares de vivência urbana, sendo também ali que se processa parte significativa do comércio informal. Já na cidade de pedra e cal, a avenida vai conectando os principais largos e praças.

Esse eixo funciona ainda como divisor longitudinal da Ilha.
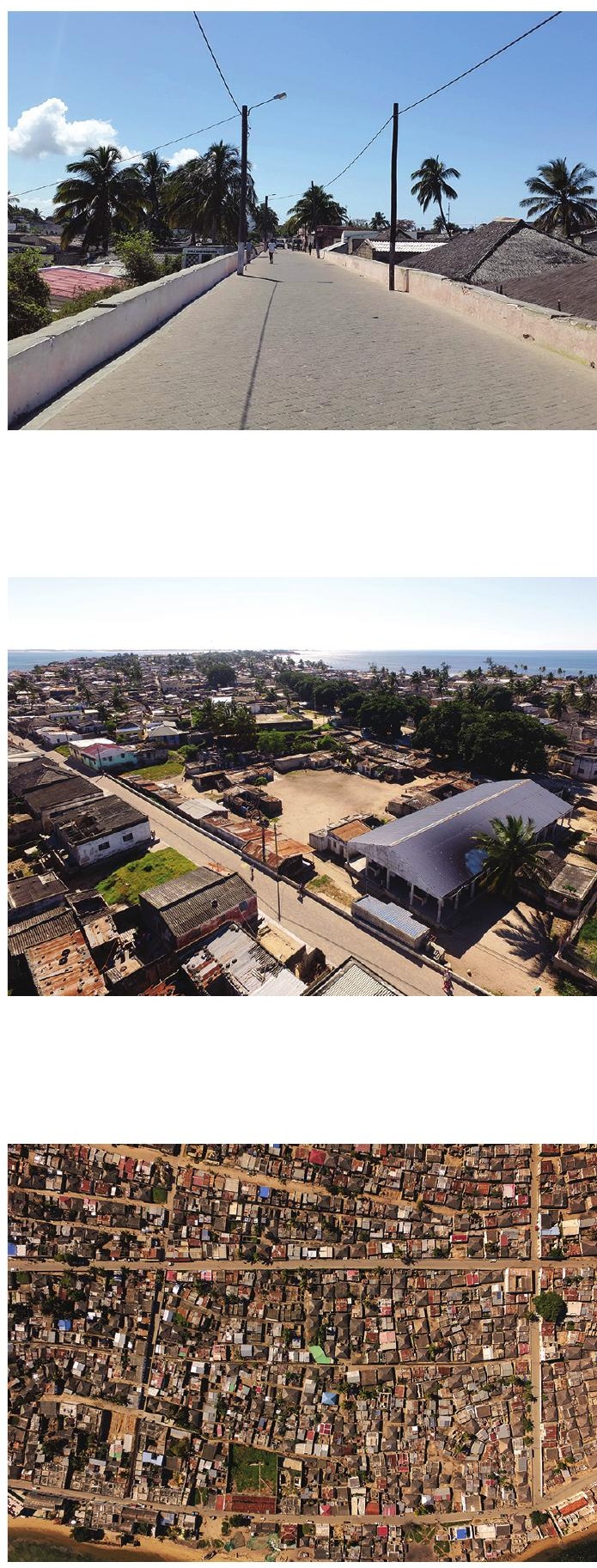
O tecido urbano da cidade de pedra e cal é formado por um sistema de quarteirões, largos e praças, estruturados e interligados por ruas e travessas que asseguram a conexão entre a costa e a contracosta. Os mais emblemáticos edifícios da cidade - Fortaleza de São Sebastião, Palácio, Capela e Torre de São Paulo, Igreja da Misericórdia, Convento de São Domingos, Câmara - tendem a articular-se com praças e largos como, por exemplo, o Campo de São Rafael, o Largo de S. Paulo ou o Largo do Mercado. São espaços públicos razoavelmente definidos, estruturados e equipados mas, conforme já registado, pouco usados pela população.

Foi a partir desta, aqui sumarizada, visão de conjunto, que a oficina teve de escolher os espaços sobre os quais desenvolver as suas propostas. Procuraram-se casos passíveis de intervenções simples e concernentes com a realidade local, levando-se ainda em conta o facto de estarem em curso ações do mesmo escopo por parte do Município, com o apoio da UCCLA, em relação às quais seria obviamente desajustado coincidir ou colidir.
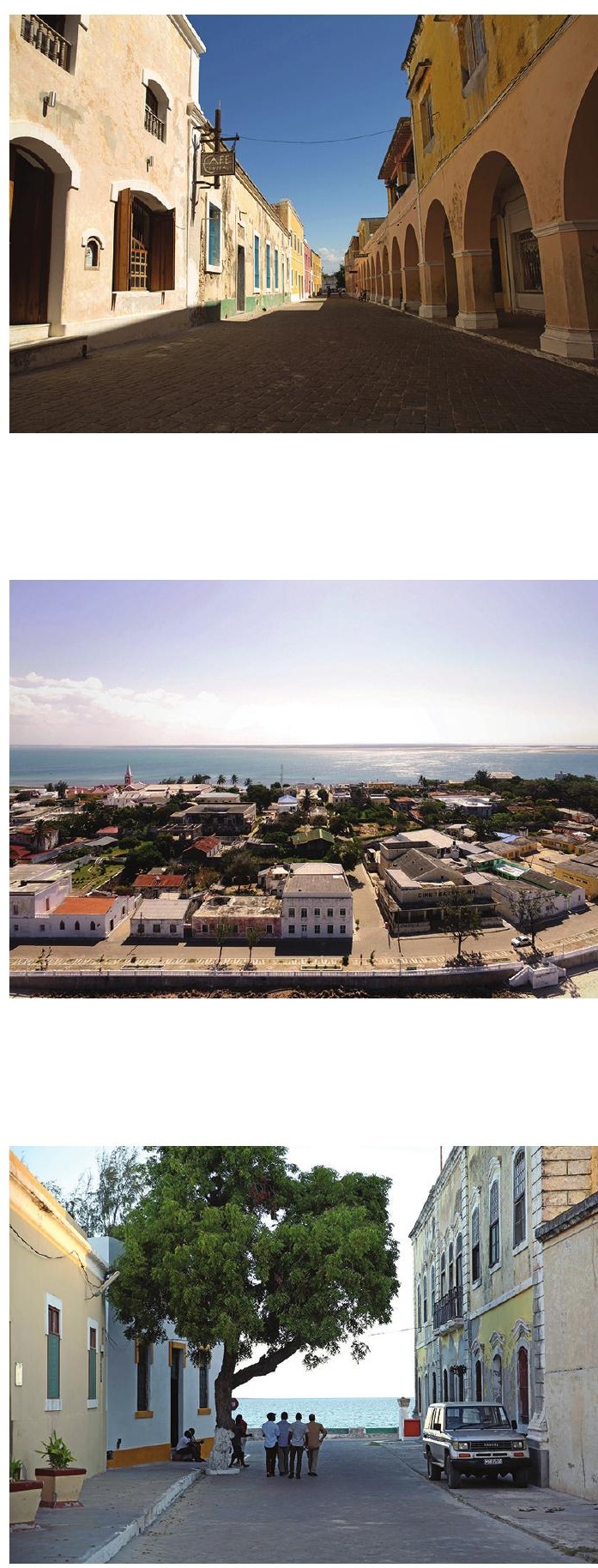
Foi assim que se selecionou o Campo de S. Gabriel, na cidade de pedra e cal (descampado adjacente à fortaleza, o qual foi denominado espaço entre praias), e o aqui designado espaço Nália (semear), no Bairro de Macaribe da cidade de macuti (constituído pelo mercado Nália e áreas adjacentes). São dois espaços que apresentam aspetos bastantes peculiares do ponto de vista dos seus processos de formação e das estruturas socioeconómicas e formais, requerendo, assim, diferentes formas de intervenção.

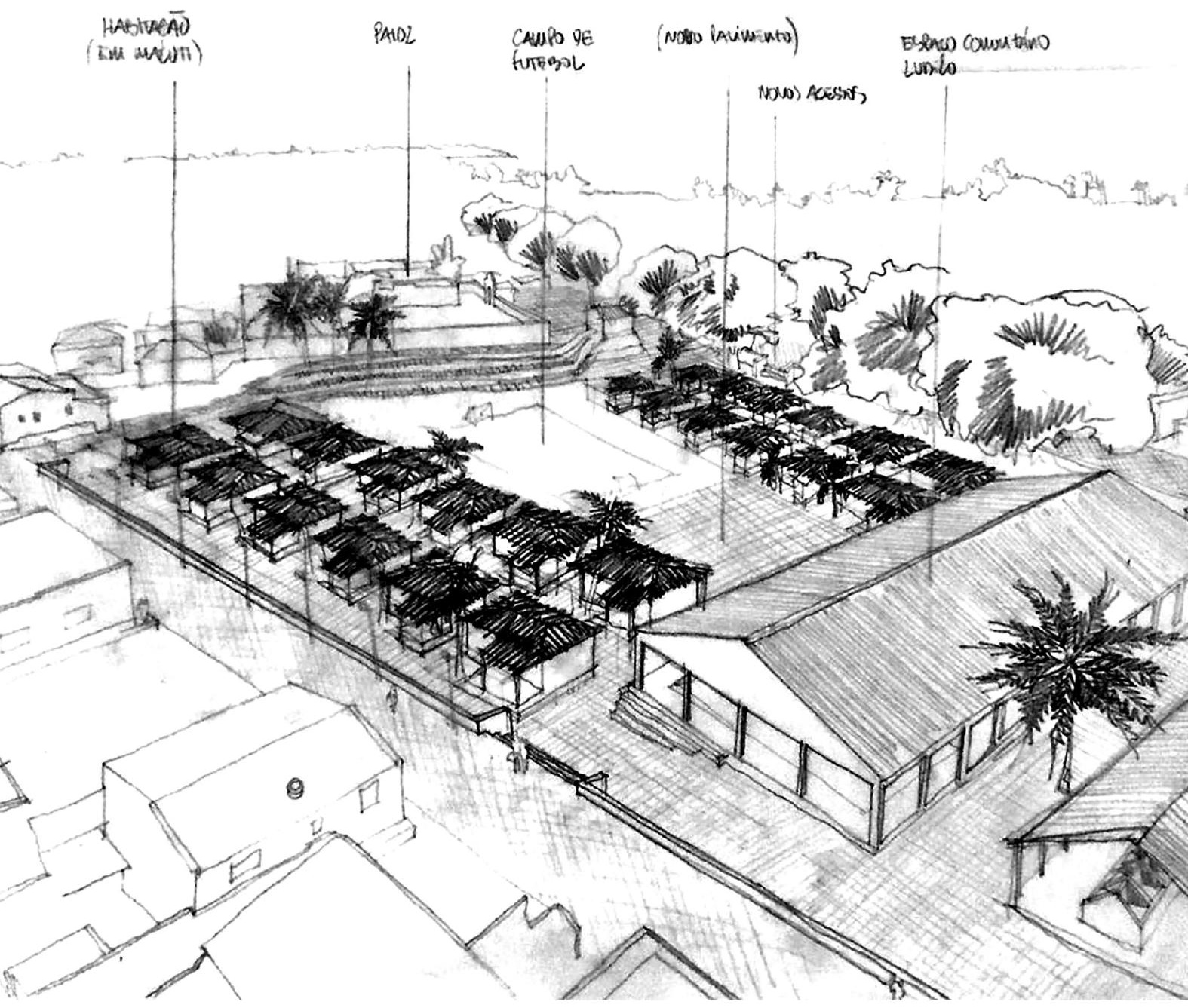




\section{AS PROPOSTAS}

\subsection{Espaço Nália}

O espaço Nália é delimitado a sudeste pela Avenida 25 de Junho, a noroeste pela Rua da Solidariedade, a nordeste pela Cisterna e a sudoeste pela antiga MCel. É um espaço bem contido, até porque está cerca de quatro metros abaixo das ruas que o circundam, o que dificulta a circulação de veículos, a sua drenagem e saneamento, em especial quando ocorrem chuvas intensas, sendo objeto de frquentes inundações. No espaço está construído o Mercado Nália, hoje inativo, correspondendo a um conjunto coberto de bancadas em betão utilizado por crianças e adultos como espaço de lazer e descanso. No perímetro existem várias construções precárias, por regra arrendadas. Mas o fulcro da área é um espaço vazio onde se pratica futebol.

A nossa proposta visa uma intervenção contida, integradora e controlada, tendo em conta os edifícios situados na periferia, como são os casos da cisterna e da Capela de São Francisco Xavier, mas também do mercado e até mesmo as construções mais precárias. Pretende-se criar um espaço multifuncional, arborizado e com boa acessibilidade.

Neste sentido e visando uma reorganização espacial, propõe-se a remoção de algumas das construções precárias e construção de novos edifícios para habitação com melhores condições de habitabilidade. Prevê-se a implementação de novos arruamentos que melhorem os acessos e a ventilação do local. Ao longo dos percursos e dos espaços mais desafogados, propõe-se a plantação de árvores de espécies endémicas na região.

Foi considerado fundamental manter o espaço central como lugar para a prática de futebol, acrescentando alguns equipamentos que viabilizem a realização de outros eventos desportivos e culturais. No antigo mercado Nália foi proposta a remoção da maioria das bancadas, com vista à conformação de um espaço amplo e coberto para reuniões comunitárias e prática de desportos de salão (basquetebol, futsal, etc.).

Propõe-se também a instalação de equipamentos públicos, nomeadamente uma lavandaria comunitária, sanitários públicos, bem como a instalação de iluminação pública e de um sistema de recolha de lixo. 


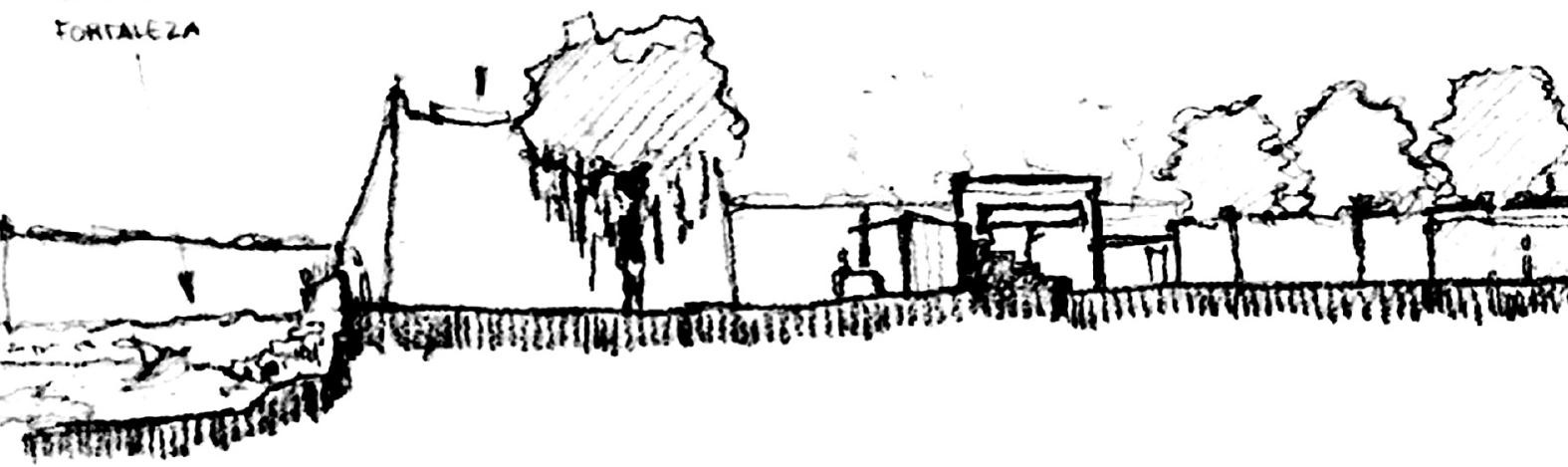

\subsection{Espaço entre praias/ Campo S. Gabriel}

O espaço entre praias aglutina quatro de elevada importância social e histórica: Fortaleza de São Sebastião, Praia da Fortaleza, Praia das Rochas e Campo Municipal de São Gabriel. Este espaço é limitado pela fortaleza, a nordeste, pelo parque, a sudoeste, pela Praia da Fortaleza, a nordeste, e Praia das Rochas, a sudeste. É um amplo descampado, sem construções, pouco utilizado pela população, exceto em dias festivos e de jogos de futebol, nos quais se verifica um elevado afluxo de pessoas e veículos.

A proposta visa catalisar novas perspetivas e experiências espaciais, sendo um dos objetivos centrais a interação das quatro zonas. Para isso, é fundamental atenuar a barreira visual e a tensão criadas entre o muro do campo municipal e a fortaleza, através da sua remoção parcial e o melhoramento da circulação pedonal.

Em termos de acessibilidade, a proposta desenvolve a ligação entre as duas praias, dando continuidade à já existente pavimentação da marginal. Propõe-se a abertura de novos percursos e espaços de permanência e lazer, diretamente relacionados com a fortaleza e de acordo com a proposta de reabilitação produzida pela respetiva oficina. Prevê-se a arborização de toda a área, a colocação de sanitários públicos, assim como a relocalização das barracas existentes junto à praia para um espaço interior, proporcionando maior dinâmica e atração de mais gente ao local.

Em suma, a intervenção pretende promover um espaço único, aglutinando os espaços contíguos de forma harmoniosa e cuidadosa, tendo sempre em conta o ambiente envolvente, as cargas histórica e simbólica e conferindo-Ihe legibilidade e fruição. 


\section{MPO DE}

STEBOL
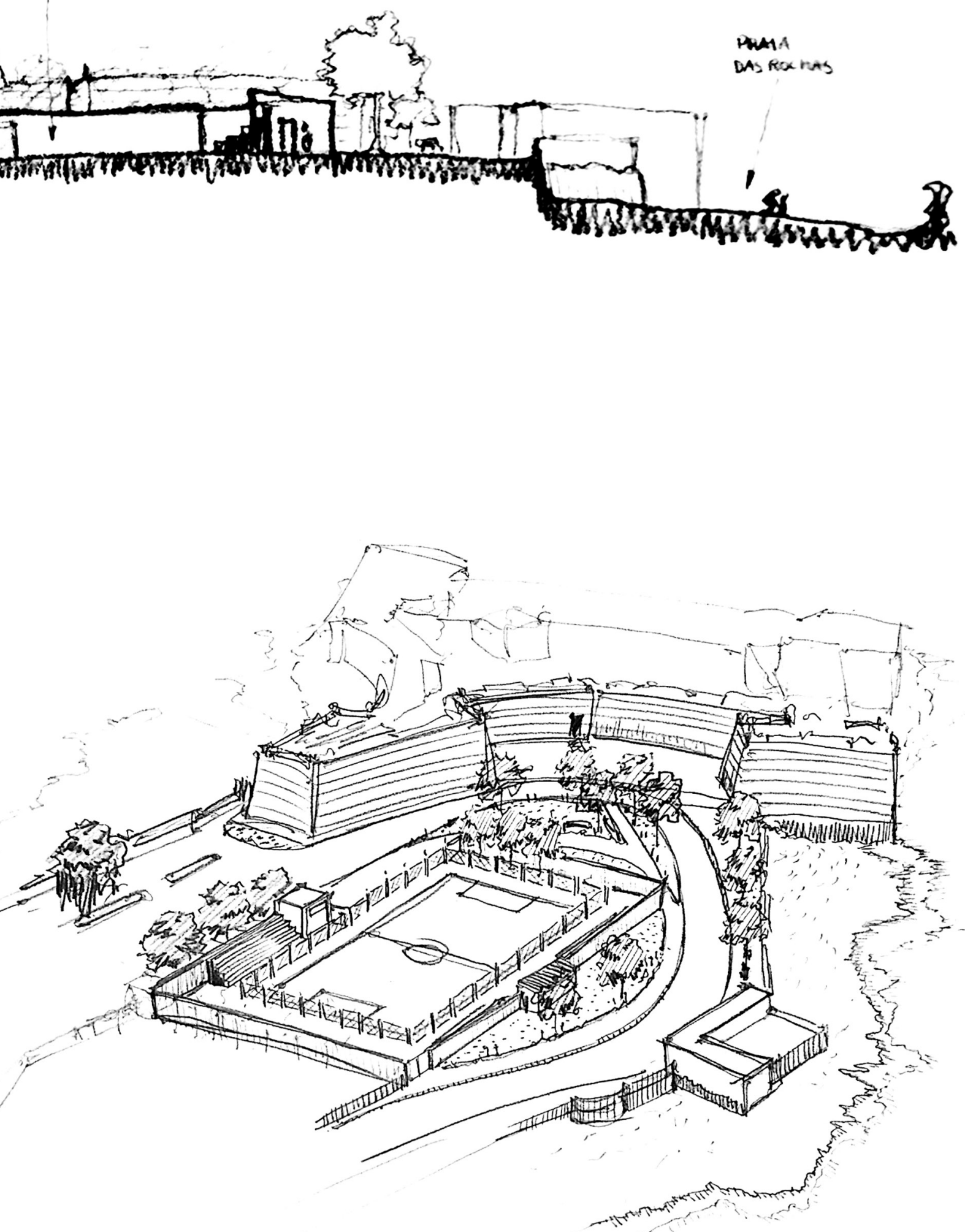


\section{NOTAS FINAIS GERAIS}

Em todo o processo de análise ficou patente que na cidade de pedra e cal os espaços públicos estão formalmente definidos, evidenciandose, porém, uma carência de elementos que potencializem a vivência urbana, mantendo-se a sua amplitude. Nesse sentido, as principais recomendações para a sua melhoria consistem numa seleção de mobiliário urbano, essencial para a vivência desses espaços, nomeadamente momentos de pausa, repouso ou lazer aos transeuntes e utentes habituais. Considerou-se também fundamental melhorar a iluminação pública e incrementar a arborização que é escassa, está doente e envelhecida.

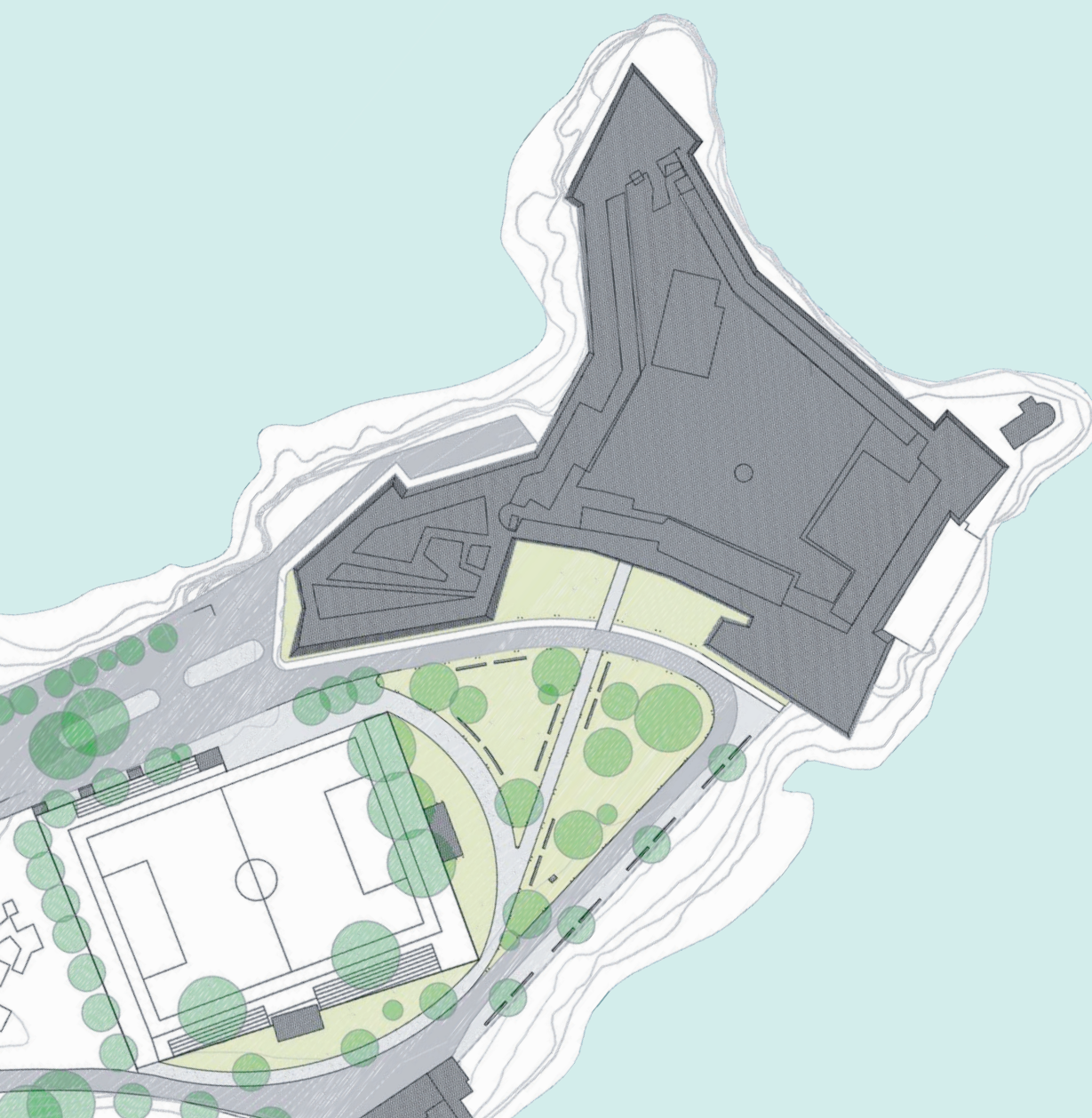


Na cidade de macuti, sem prejuízo das áreas de habitação, os espaços públicos precisam de ser reestruturados e ganhar dimensão. Neste caso, as recomendações são no sentido de se proceder à pavimentação de algumas áreas, evitando o estreitamento acentuado das ruas com novas construções, permitindo maior mobilidade. A arborização dos espaços é, também aqui, essencial para a criação de microclimas e espaços mais agradáveis, sendo também fundamental o melhoramento na iluminação pública.

As intervenções propostas consideram sempre os princípios de adequação técnica, ambiental e cultural, de modo a evitar transformações agressivas ao carácter da própria llha.

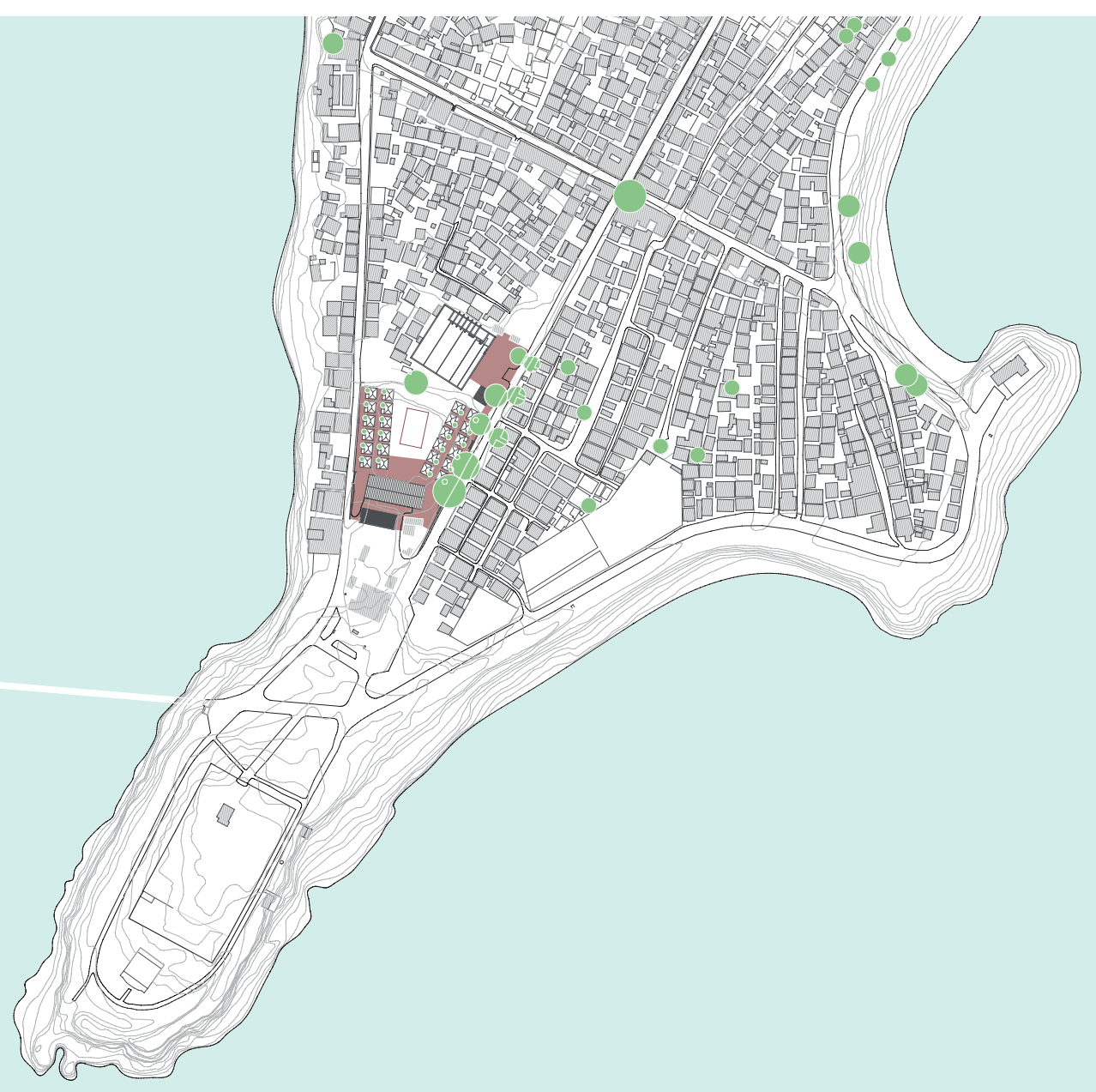




\section{REFERÊNCIAS BIBLIOGRÁFICAS}

CHEN, Arthur et al. (2011), Preliminary study on public spaces in Ilha de Moçambique. Center for World Heritage Studies: University of Minnesota.

LOBATO, Alexandre (1945), A Ilha de Moçambique (Monografia). Lourenço Marques: Imprensa Nacional.

SNPE, Secretaria de Estado da Cultura de Moçambique; Arkitektskolen i Ãrhus, Denmark (1986), Ilha de Moçambique, relatório - Report 198285. Moçambique e Dinamarca: Secretaria de Estado da Cultura e Arkitektskolen i Ãrhus. 